\title{
CONVENTIONAL OPEN EARLY APPENDECTOMY IN MANAGEMENT OF APPENDIX LUMP
}

\author{
Amanjee Bharti', Ram Nagina Sinha², Anuradha Sharma3 ${ }^{3}$ Pallavi Kumari ${ }^{4}$, Kumari Neha ${ }^{5}$ \\ ${ }_{1}^{1}$ Assistant Professor, Department of General Surgery, F. H. Medical College and Hospital, Etmadpur, Agra, Uttar Pradesh, India. \\ 2 Professor, Department of General Surgery, F. H. Medical College and Hospital, Etmadpur, Agra, Uttar Pradesh, India. \\ 3Postgraduate Student, Department of Pathology, F. H. Medical College and Hospital, Etmadpur, Agra, Uttar Pradesh, India. \\ ${ }^{4}$ Final Year MBBS Student, F. H. Medical College and Hospital, Etmadpur, Agra, Uttar Pradesh, India. \\ ${ }^{5}$ Final Year MBBS Student, F. H. Medical College and Hospital, Etmadpur, Agra, Uttar Pradesh, India.
}

\begin{abstract}
BACKGROUND
ABSTRACT

Acute appendicitis is one of the most common causes for abdominal emergency worldwide. Its causes vary from the ones requiring medical management to those necessitating surgical intervention. Even though clinical examination and assessment are the mainstay of diagnosis, biomarker and imaging add valuable evidence. The management is also based on the clinical categories like simple non-perforated and complex gangrenous or perforated appendicitis. Clinical features include fever, raised W.B.C. count, increased C. Reactive Protein and presence of pus in abscess, but these features are by and large absent in case of lump in the appendix. In the present study, we attempted the conventional open early appendectomy in lump. The method used was examination through necked eyes and tissue contact with hands. We found visibility and cleanness to be very good than laparoscopic appendectomy in the management of appendix lump. The faster diagnosis and management are essential for the survival of patients in appendix lump. Hence, this study is under taken to study the conventional open early appendectomy in predicting the outcome.
\end{abstract}

\section{MATERIALS AND METHODS}

This hospital based prospective interventional study was conducted for a period of six months (October 2017 to March 2018) in the department of general surgery in F.H. Medical College and Hospital, Agra. U.P. Acute appendicitis is most common acute surgical emergency. More than $10 \%$ patients with acute appendicitis present with appendicular lump. The management of appendix lump remains controversial as some clinicians prefer conservative treatment and others go for operative procedures. This study was carried out to evaluate the outcome of conventional open early appendectomy in appendix lump. This methodology is since ancient to recent times been in practice with very successful results. 30 patients diagnosed to have appendix lump based on triple assessment (by history, clinical examination and investigations like radiological imaging and lab tests) were included and the conventional open early appendectomy was performed.

\section{RESULTS}

Among 30 patients included in the present study there were 20 males and 10 females ranging from 10 to 60 years. Two patients had gangrenous adhesions in caecum for whom, ileocaecal anastomosis was done. Abdominal cavity was cleaned, and drain was placed for 3 to 4 days. The operative time was 60 minutes to 120 minutes. The hospital stay in 2 patients was 15 days and in remaining 20 patients was 7-10 days. No major post-operative complications were noted. Only 2 patients developed complications which were treated spontaneously by dressing and higher antibiotic medication. In the present study, the overall success rate was $98 \%$ and $2 \%$ developed complications.

\section{CONCLUSION}

Conventional open early appendectomy is feasible and safe in secondary care hospitals than laparoscopic appendectomy. The conventional open early appendectomy avoids the need for readmission and also avoids misdiagnosis. This procedure has been performed under the naked eye-vision and direct touch to tissue by the head-heart-hands involvement. This method is associated with less morbidity, mortality.

\section{KEY WORDS}

Conventional Appendectomy, Lump, Perforation, Appendicitis. HOW TO CITE THIS ARTICLE: Bharti A, Sinha RN, Sharma A, et al. Conventional open early appendectomy in management of appendix lump. J. Evolution Med. Dent. Sci. 2018;7(50):5394-5397, DOI: 10.14260/jemds/2018/1193

'Financial or Other Competing Interest': None.

Submission 31-10-2018, Peer Review 24-11-2018,

Acceptance 30-11-2018, Published 10-12-2018.

Corresponding Author:

Dr. Ram Nagina Sinha,

Professor,

Department of General Surgery,

F. H. Medical College and Hospital, Etmadpur, Agra,

Uttar Pradesh, India.

E-mail:drrnsinha33@gmail.com

DOI: $10.14260 /$ jemds $/ 2018 / 1193$

\section{BACKGROUND}

Appendicitis is a chronic, acute infective and inflammatory pathological condition associated with various problems, Features and abdominal Emergency. (1)

There are commonly two types of appendicitis. The one is non-obstructive type for which progress is slow and another is obstructive type which progresses very fast leading to gangrene and perforation(2). The common causative factors are infection by microbes and others are foreign body and faecolith. The appendix lump is the commonest swelling or lump in the right iliac Fossa. (3) 
The lump develops late in the course of appendicitis and complicates the condition as an appendix lump. This is the end result of walled off perforation, represent a pathological spectrum from simple to complex problems. The treatment of lump is controversial. Traditionally lump was treated by conservative management and which is followed by interval open early appendectomy by most of the surgeons than laparoscopic appendectomy in appendix lump. [4]

Harvey Cushing said, Surgeon requires a special combination of head - heart - hands. Career in surgery is attractive. The both hands right or left are used for either satisfaction. The paradigm shift in surgical practice happened when the hands of surgeon were taken away from the body of patient by laparoscopic surgery. Sir John Erickson, queen's surgeon in 1937 thought that a surgeon will never be able to manipulate the inside without our hands touching to structures directly. The surgery is a practice-based science. The Eyes and hands are essential for open operation than laparoscopic surgery technology.(5)

The laparoscopic, robotic surgeries are costly and time taking. These are not available everywhere and not useful in complex condition. So traditional open appendectomy approach is in practice everywhere by surgeons in rural and urban hospitals.(6) The open early surgical intervention is known to be the proper therapy.[7]

The conventional open early appendectomy is being curative. This ensures early productivity to the profession and higher compliance towards optimum output to patient. So that the method used in the present study has been the standard treatment for all forms of appendix lump and other pathological condition of the appendix. It represents an important burden on health delivery system. Appendectomy frequently performed globally with international variation in services. The estimated life time risk is around $7 \%\left({ }^{8}\right)$

Acute appendicitis occurs in the $2^{\text {nd }}$ or $3^{\text {rd }}$ decade of life which is more among males. Infection by microbiome aerobic and anaerobic bacteria, Faecolith, Foreign body, Lymphoid Hyperplasia, Proliferation of nerves fibres, activation of Neuropeptide are leading causative factors.

Most of the times, the disease is aggressive in nature. One of the serious complications of appendicitis is appendix lump. After an acute attack if not treated adequately with Surgery, the body tries to contain the infection. In this process the nearby intestine and omentum try to isolate the infected appendix from all surrounding sides leading to formation of lump. This may be leads to abscess formation, perforation of appendix, septicaemia and development of the lump.

Acute Appendicitis is an exemplary condition of acute infected appendix. These patients are usually treated conservatively. The surgery at this stage is risky. If the lump progresses the conservative treatment is abandoned. The intervention may be opted in favour of open surgical intervention. Surgeon has to observe the potentially grave situation and decide definite surgery to a later date.

All these carry risk for the patients. In this part of India there are poor people who do not have any other option rather than to accept the situation. They come late because of various reasons one important aspect being their financial status. Initially they expect this pain in abdomen may not be severe and go away automatically, better to wait rather than to go to a doctor and spend money which is wastage. That amount can be used to feed them-selves. But in the long run when it aggravates, they even sell all their property to get treated.

Treatment facilities in terms of man power and infrastructure is lacking in this part, added to it is the high pricing of drugs, indifferent attitude of Government services, and providing agencies compels the poor to wait at home expecting auto cure and go to quack or indulge in folk remedies.

Appendicitis is an inflammation of the appendix. Symptoms commonly include right lower abdominal pain, nausea, vomiting, and decreased appetite. However, approximately $40 \%$ of people do not have these typical symptoms. Severe complications of a ruptured appendix include widespread, painful inflammation of the inner lining of the abdominal wall and sepsis.

Appendicitis is caused by a blockage of the hollow portion of the appendix. This is most commonly due to a calcified "Stone" made of faeces. Inflamed lymphoid tissue from a viral infection, parasites, gallstone, or tumors may also cause the blockage. This blockage leads to increased pressures in the appendix which leads decreased blood flow to the tissues of the appendix, and bacterial growth inside the appendix causing inflammation. The combination of inflammation, reduced blood flow to the appendix and distention of the appendix causes tissue injury and tissue death. If this process is left untreated, the appendix may burst, releasing bacteria into the abdominal cavity, this leads to increased complications, peritonitis and development of appendix lump.

The diagnosis of appendicitis is largely based on the signs and symptoms. In cases where the diagnosis is unclear, close observation, medical imaging and laboratory tests may be helpful. The two most common imaging tests are an ultrasound and computed tomography (CT scan). CT scan has been shown to be more accurate than ultrasound in detecting acute appendicitis. However, ultrasound may be preferred as the first imaging test in children and pregnant women because of the risks of radiation from CT scans exposure.

The standard treatment for recurrent acute appendicitis is surgical removal of the appendix. This may be done by an open surgery in the abdomen. The surgery decreases the risk of side effects or death which is associated with rupture of the appendix. Antibiotics may be equally effective in certain cases of non-ruptured appendicitis. The most common and significant causes of severe abdominal pain that comes quickly in appendicitis. In 2015 about 11.6 million cases of appendicitis occurred which resulted in about 50 to 100 deaths. In the United States, appendicitis is the most common cause of sudden abdominal pain requiring surgery. Each year in the United States, more than 300, 000 people with have their appendicitis which was surgically removed. Reginald Fitz is credited with being the first person to describe the condition in 1886.

The management of appendix lump is surrounded by controversy. Traditional management has been conservative. The interval open appendectomy performed after weeks when the lump had been decreased. This remains the most common approach at many centers in the world. Recently, an increasing number of studies have challenged this approach. A conservative management is still a highly acceptable 
approach for appendix lump. This should be followed with open interval appendectomy especially in patients with persistent right iliac fossa pain and tender lump. We recommend initially conservative approach to the management of appendix lump especially in our environment and later on open early appendectomy is the choice in the management of lump.

Appendicitis is the most common cause of pain requiring surgery. Fitz et al. described and diagnosed appendicitis in 1886 for the first time, and McBurney performed an appendectomy in 1894 for the first time. Since then, the open appendectomy has been established as the standard treatment for appendicitis. Nevertheless, $2-7 \%$ of appendicitis patients do not have simple appendicitis, but have appendicitis that manifests itself with complex features such as lump of appendix. The right lower quadrant lump is due to acute inflammation in connective tissues. When emergency surgery is performed on such cases, due to inflammation in a wide area within the abdominal cavity, adhesion of the intestines, sepsis after surgery, fluid collection within the abdominal cavity, healing of surgical wounds has been shown to be delayed substantially. Therefore, recently, for patients suspected of having appendicitis associated with appendix lump, the trend has been to perform conservative treatments for example, ultrasound-guided percutaneous drainage and antibiotic treatments first and subsequently to perform an interval open early appendectomy after a certain time. The standard treatment protocols have not been established. This issue is still controversial. In this regard the interval appendectomy being always required because of the risk of recurrence of appendicitis after conservative treatments. Thus, after successful conservative treatments, an interval open early appendectomy is always necessary in lump. The recurrence rate is low. It is approximately $7 \%$, in several studies.

We conducted this study to evaluate the outcome by conventional open early appendectomy in management of appendix lump.

\section{MATERIALS AND METHODS}

This prospective interventional study on conventional open early appendectomy of appendix lump has been carried out in the department of general surgery F.H. Medical College \& Hospital. Agra (U.P).

The ethical clearance and patient's consent were taken for this study.

A total of 30 patients of acute appendicitis with lump were taken during the period of October 2017 to March 2018 in the department of general surgery of Hospital. Appendix lump was diagnosed by History, clinical examination and investigation like Blood test and ultrasound of whole abdomen \& pelvis. The diagnosis was also confirmed during operation. Pre-, per- and post- operative sequences and findings were documented in various data entry sheets.

\section{RESULTS}

Among 30 patients included in the present study there were 20 males and 10 females ranging from 10 to 60 years. Two patients had gangrenous adhesion in caecum for whom, the ileocaecal anastomosis was done. Abdominal cavity was cleaned, and drain was kept for 3 to 4 days. The operative time was 60 minutes to 120 minutes. The hospital stay in 2 patients was 15 days and rest 20 patients had 7-10 days. No major post-operative complications were noted. Only 2 patients developed complications which were treated spontaneously by dressing and higher antibiotic medication. In the present study overall success rate was $98 \%$ and $2 \%$ developed complication.

\begin{tabular}{|c|c|c|c|}
\hline Age Group & No. of Cases & Percentage & Remarks \\
\hline 10-20 Years & 10 & $33 \%$ & \\
\hline 30-40 Years & 15 & $50 \%$ & \\
\hline 40-60 Years & 5 & $17 \%$ & \\
\hline \multicolumn{4}{|c|}{ Table-1 Age Distribution. } \\
\hline
\end{tabular}

Ratio is more in 30-40 years of Age group.

\begin{tabular}{|c|c|c|}
\hline Sex & Number of Cases & Percentage \\
\hline Male & 20 & $66.5 \%$ \\
\hline Female & 10 & $33.5 \%$ \\
\hline \multicolumn{3}{|c|}{ Table 2. Sex Distribution } \\
\hline
\end{tabular}

Ratio is maximum in male sex 20 cases.

Clinical features were Pain - Right Side Abdomen, Fever, Vomiting, Right Iliac fossa lump - with tenderness and rigidity in all cases were present.

\begin{tabular}{|c|c|c|}
\hline Operative Finding & Number of Case & Percent \% \\
\hline Simple Lump (Mass Phlegm) & 20 & $66.66 \%$ \\
\hline Appendix Abscess & 8 & $26.66 \%$ \\
\hline $\begin{array}{c}\text { Dense Adhesion with } \\
\text { Omentum and Caecum }\end{array}$ & 2 & $6.66 \%$ \\
\hline \multicolumn{2}{|c|}{ Table 3. Intra Operative Finding } \\
\hline
\end{tabular}

The common per operative finding is simple lump in 20 cases

\begin{tabular}{|c|c|c|}
\hline Operation Time in Minute & Number of Cases & Percent \% \\
\hline $30-60$ Minutes & 28 & $93 \%$ \\
\hline $60-120$ Minutes & 2 & $7 \%$ \\
\hline \multicolumn{2}{|c|}{ Table 4. Operative Time } \\
\hline
\end{tabular}

Operative time were 30 to 60 minutes in 28 cases and 60120 minutes in 2 cases associated with complication.

\begin{tabular}{|c|c|c|}
\hline $\begin{array}{c}\text { Pain Abdomen Fever and } \\
\text { Anorexia }\end{array}$ & 28 Cases & $98 \%$ \\
\hline Pus Discharge and Fistula & 2 Cases & $2 \%$ \\
\hline \multicolumn{2}{|c|}{ Table 5. Post - Operative Complication } \\
\hline
\end{tabular}

Two cases were associated with complication.

\begin{tabular}{|c|c|c|}
\hline Days & Number of Cases & Percent \% \\
\hline $7-10$ days & 28 & $93 \%$ \\
\hline $10-15$ days & 2 & $7 \%$ \\
\hline \multicolumn{3}{|c|}{ Table 6. Hospital Stay } \\
\hline
\end{tabular}

The average hospital stay were 11 days. 


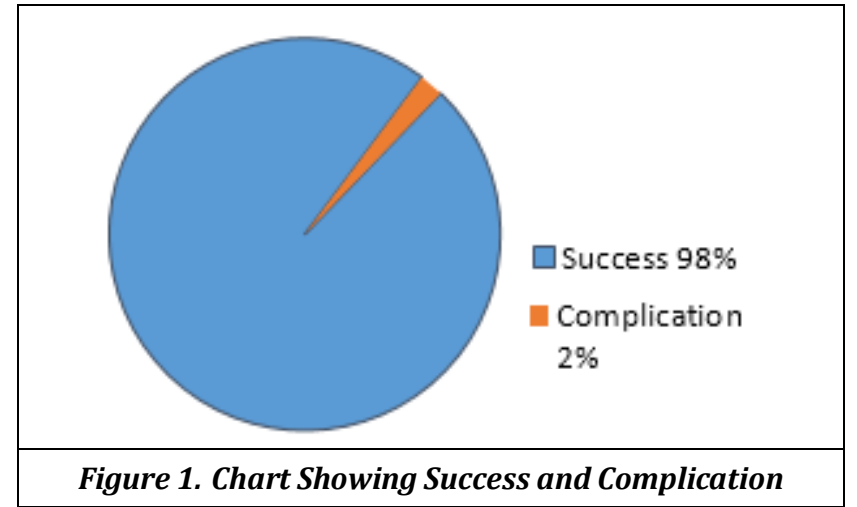

\section{DISCUSSION}

Appendix lump following appendicitis is one of the reasons for surgical intervention. There are many controversies still exits regarding management of appendix lump. Traditional treatment is conservatives and which is followed by interval open appendectomy by the surgeon.(9) In this procedure Eyevisualisation, directly tissue touching from the hidden corners, The Peritoneal Lavage, clearance of debris and purulent materials are properly possible and satisfactory.[10] The distinguish between lump, mass and abscess is not possible before operation. Open surgical manoeuvre may be used to confirmed the diagnosis. The open method is used during failures of laparoscopic and other methodology. Jordan $\mathrm{J} S$ et al and others performed 42 open appendectomy in palpable lump and recommended open early surgery in patient with appendicitis with palpable lump.(11) Horwitz J R et al and others have suggested to avoid the laparoscopic surgery approach in lump and complicated cases because of the increased risk in post-operative period. The conventional open early appendectomy in the management of appendix lump is effective procedure. It is the choice of surgeons which is safe and secured.(12). The results of our procedure proved the evaluation of works in our study. Cases had successful result $98 \%$ and in 2 cases developed complication in our series.

\section{CONCLUSION}

Appendix lump remains a hot spot for surgeon. Various factors like age, sex surgical techniques and treatments are associated with varied morbidity and mortality. Conventional open early appendectomy is more effective than any other methodology.. This technique is totally curative, less time consuming, requires short hospital stay, less costly and has better compliance. It is feasible at secondary, tertiary care and teaching hospitals with optimum results and productive outcome.

\section{REFERENCES}

[1] Bhangu A, Soreide K, Di Saverio S, et al.Acute appendicitis: modern understanding of pathogenesis, diagnosis and management.The Lancet 2015;386(10000):1278-87.

[2] Gupta N,SapireJM,Marrinan G,et al. Some stones are precious-extraluminal appendicoliths.Indian of Surgery 2016;78(6):507-8.

[3] Das S. A manual on clinical surgery. Acute appendicitis. 9thedn. Kolkata, India: Dr. S. Das Publisher 2011: p. 468.

[4] De U, Ghosh S. Acuteappendectomy for appendix mass: a study of 87 patients. Ceylon Med J 2002;47(4):117-8.

[5] AgrawalN.Even handed future of surgeryambidextrous, serious gamers with innate left hand laterality. Indian Journal ofSurgery 2016;78(6):50910.

[6] ArnbjornssonE. Management of appendiceal abscess. CurrSurg 1984;41(1):4-9.

[7] Okafor PL, Orakwe JC, Chianakwana GU. Management of appendiceal masses in a peripheral hospital in Nigeria: review of thirty cases. World J Surg 2003;27(7):800-3.

[8] Nitecki S, Assalia A, Schein M. Contemporary management of the appendiceal mass. Br J Surg 1993;80(1):18-20.

[9] Garg P, Dass BK, Bansal AR, et al. Comparative evaluation of conservative management verse early surgical intervention in appendiceal mass - a clinical study. J Indian Med Assoc 1997;95(6):179-80, 196.

[10] Thomas DR. Conservative management of the appendix mass. Surgery 1973;73(5):677-80.

[11] Jordan JS, Kovalcik PJ, Schwab CW. Appendicitis with a palpable mass. Ann Surg 1981;193(2):227-9.

[12] Horwitz JR, Custer MD, May BH, et al. Should laparoscopic appendectomy be avoided for complicated appendicitis in children? J PediatrSurg1997;32(11):1601-3. 